\title{
Concept, Nature and Samples of Aggression and Its Controlling Techniques with Emphasis on the Islamic Approach
}

\author{
Zohreh Mousazadeh ${ }^{1} \&$ Nasrin Asgharzadeh ${ }^{2}$ \\ ${ }^{1}$ Department of Educational Sciences, Imam Sadiq University, Tehran, Iran \\ ${ }^{2}$ Science and Research Branch, Islamic Azad University, Tehran, Iran \\ Correspondence: Nasrin Asgharzadeh, Science and Research Branch, Islamic Azad University, Tehran, Iran. \\ E-mail: fashira.unique@gmail.com
}

Received: December 19, 2011 Accepted: January 19, $2012 \quad$ Published: May 1, 2012

doi:10.5539/ass.v8n6p140

URL: http://dx.doi.org/10.5539/ass.v8n6p140

\begin{abstract}
The current paper addresses concept, nature, samples and types of aggression in order to define them, and to study different prevention and control methods from different perspectives especially from an Islamic approach. Qualitative methods and content analysis tools were used in this research. The statistical community consisted of 48 hadith and historical books, which were selected objectively and used as samples. The results of the research showed that the infallibles emphasized seven methods (tolerance, negotiation, affinity among members, exercising of power, relation control, mediation, arbitration and consultation) to solve and to manage aggression. A high percentage of usage of aggression control and prevention methods was found in 70 hadith and historical documents. They imply that in conflicts the infallibles used tolerance and meditation with greater frequency (\%17.14 and \%14.28) whereas arbitration was used with lesser frequency (\%10) to prevent and to control aggression. Furthermore the infallibles were only seen in conflicts if they themselves were involved or if they were acting as a third party.
\end{abstract}

Keywords: aggression, prevention, control, Islamic approach, conflict resolution

\section{Introduction}

Nowadays violence and aggression are considered as a major global issue and their psychological and physical destructive effects are viewed as interpersonal and in-group issues. As roots of many crimes, great odds, deviations and even wars must be sought in violence and aggression, experts have emphasized scientific study of aggression and violence in order to identify their risk factors and triggers and also to provide preventive strategies.

Aggression stems from "aggredior" which means to attack or to get close to something. The term is labeled "omnibus", which means it can be studied from various dimensions (Ramirez, 1998, 2003). Aggression has two different aspects: objectivity (action), subjectivity (emotions). Objectivity indicates that aggression is a practical, explicit and external behavior however subjectivity signifies that aggression is associated with an inner feeling. The feeling is a combination of thoughts, emotions and behavioral tendencies which lead to aggressive behaviors. In numerous definitions, aggression is considered as behaviors combined with violence. It encompasses any behaviors which have an intention of physical and psychological harm to another person. In addition any destructive or punitive behavior towards people and objects is called aggression (Ramirez, 2003, 1998 and Corsini, 2002).

In different categories, dual and distinct issues have been presented from different aggressive behaviors in the forms of: verbal vs. nonverbal aggression, direct vs. indirect aggression, instrumental vs. hostile aggression, active vs. collective aggression, individual vs. collective aggression and proactive \& offensive vs. reactive \& defensive aggression (Ramirez, 2003, 1998, Woolfolk, 2004, Berger 2006, Petterson, 2008).

While studying aggression, it is necessary to consider three factors: biological, social and psychological; this is because detailed explanation of aggression is not provided without considering interaction of aggressive behaviors with recognition, emotion and social affairs. Theoretical perspectives, explaining the concept of aggression, are considered as two approaches: nature-oriented and training-oriented. In the approach of 
nature-oriented, the intrinsic and internal nature of aggression is emphasized and aggressive behavior is considered spontaneous and unavoidable.

Freud, Konrad Lorenz and Wilson's opinions and biological approaches can be reckoned as critical theories in this approach. Training-oriented approach emphasizes the role of training and gaining aggressive behaviors and mainly knows aggression as a response to adverse environmental conditions, such as frustration, harrowing and distressing events and environmental threats. The training-oriented approach is based on theories of frustration, social learning, social cognition, script, cultivation, executive cognitive functioning (EFC) and even multi- factor theories.

Factors affecting the incident of aggression and its strength have been discussed by various theoretical perspectives: cognitive distortions, social information processing, cognitive schemes, communication skills, medias, biological factors, individual differences, psychological processes, growth conditions and other factors such as environmental ones (air pollution, noise and population density), alcoholism and addiction to narcotics and hallucinogens.

The main step in terms of achieving peace, tranquility and public safety is explaining that there is no gene or specific biological structure for incidence of aggression, violence and guilt. Thus achieving of safety, tranquility and peace is possible based on scientific principles (Ramirez, 1996, 2000). The most fundamental step to prevent and to control aggression is establishing and strengthening the major belief that aggression is not a global phenomenon and inevitable. It is manageable under the influence of any factor even the biological one. Aggression is a complicated concept and is determined by multiple factors. It is preserved in various ecological systems (family, peer group and school). Although biological and genetic factors increase the risk of aggression among some people, the environmental conditions have more influence on their mental health problem (such as aggression). Social and economic diversity directly effect on children aggression and indirectly on different mechanism including methods of parenting and parental mental health (Domitrovich, Celene E, 2003). Thus achieving security in any society requires mutual cooperation and intervention in various educational, cultural, social, political, economic and environmental levels.

Public education (community level), family education (in couples and relationships of parents and children) and formal educations (in school) are considered as preventive measures in the training of adjustment and aggression control tactics. Progress, development and training in all aspects of human life smooth the way to achieve comfort, security and sustainable peace and so to prevent aggression and violence. Is it possible to prevent aggression? The theorists who have raised the perspective of biological and instinctive nature of aggression look pessimistically to control aggression. Aggression control is considered difficult by them, although they believe if aggression can lead to more healthy and convenient directions, its destructive consequences will be reduced.

Social learning theorists believe that environmental factors lead learning and persistence of aggressive behaviors. Therefore it can be slightly controlled and prohibited by reinforcing non-aggressive patterns, punishing aggressive patterns, and reinforcing incompatible behaviors with aggression (Abolma'ali, 2010).

Followers of cognitive approach know hostile relationships and cognitive distortions as the main factors of aggressive behaviors. They know the following factors very useful in preventing aggression: preventive interventions of cognitive-behavioral such as self-cognition, anger control training, social skills training, cognitive and social skills training (Touzandehjani and colleagues, 2002).

Aggressive people's solutions are less community friendly and rarely with assertiveness skills. They often value the aggressive solutions as the positive ones, attribute hostile intentions to the other's behavior, do not demonstrate sensitivity to some social cues, use aggressive solutions to achieve their goals, do not have enough ability to use communication skills (Abolma'ali, 2010 and Ramirez 2000). Due to the damaging effects of aggression on people's psychological and social life, preventive interventions need to be considered seriously.

From the Islamic perspective, on the one hand aggression and violence are considered as a moral corruption factor and the spiritual fall of people, groups and societies and also war, rape, terror, destruction, assault and murder are obvious evidence of violence and aggression, on the other hand the different explanation, states that the issue and the way of using it, are the survival factors of many humans, societies, cultures and civilizations. In this regard, there are some issues such as defense of water and soil and homeland, honor and dignity, fervor and zeal, religion and culture, punishment and execution of retribution and etc which are often considered as symbols of aggression regardless of their background and basis. They are even assessed negatively without knowing various aspects (a group of authors 2004). According to status and importance of the subject, the current research attempts to describe and to explain concept, nature, samples and viewpoints. 


\section{Method and Data Analysis}

The study is a descriptive-analytical one. In this method, target samples were extracted, classified and coded with using verses and hadith. Then to determine the validity and reliability of components, a questionnaire put together by the researcher was designed based on the results and so was validated by inquiring specialists' and experts' opinion in both educational sciences and the Islamic studies fields.

In the current paper, due to exact texts investigating, the qualitative content analysis method was used. References of the related Hadith were extracted with restudying and reviewing references and were categorized. Triangulation method of experts was used in the research in order to validate the research findings and to discover and minimize the abuse in results. Thus a questionnaire put together by the researcher which contained extracted evidences was designed and given to 15 experts of educational sciences and the Islamic theology fields. The questions which their agreement coefficients were under 0.6 were deleted from the questionnaire.

\section{Population, Sample and Sampling Method}

Population and the sample of this research consist of 48 Hadith and historical books related to the lives and speeches of the infallibles (peace be upon them) and some relative chapters from Baharolanvar, Osole kafi, Vasael-o-shi'a. Twenty experts and scholars in the field of educational sciences and the Islamic theology had been chosen to code extracted categories and subcategories and to determine the reliability of the research; they also stated their agreement with the obtained result. According to the purpose of the research, the sampling procedure was purposive.

87 chapters from the aforementioned books were chosen as samples in order to carry out the qualitative method of the research. Using inductive analysis, information was extracted, classified and coded in terms of categories and subcategories. In order to determine the reliability of the research, the categories and subcategories were chosen according to the results of a questionnaire put together by the researcher. Experts in the Islamic studies and educational sciences took this questionnaire, and then according to their views and opinions categories and subcategories were chosen.

\section{Findings}

In this research extracted categories and subcategories were given to the experts in order to be coded from Hadith and historical documents. A percent agreement formula $(\mathrm{PA}=\mathrm{AIN})$ was applied to determine the extent agreement of the experts. In the formula, the agreement among the experts is divided by the total number of encoded data.

Table 1 shows the validity of categories of a questionnaire put together by the researcher.

Table 1.

\begin{tabular}{cccc}
\hline Number of total questions & $\begin{array}{c}\text { Cronbach's alpha of total } \\
\text { questions }\end{array}$ & Mean of total questions & $\begin{array}{c}\text { Variance of total } \\
\text { questions }\end{array}$ \\
\hline 48 & 0.915 & 3.698 & 0.877 \\
\hline
\end{tabular}

Central tendency of the questionnaire put together by the researcher for assessing conflict management techniques shows in Table 2.

Table 2.

\begin{tabular}{clccc}
\hline No. & \multicolumn{1}{c}{ Category } & mean & Scale deviation & Standard deviation \\
\hline 1 & Tolerance & 2.46 & 1.30 & 1.69 \\
2 & Negotiation & 4.04 & 0.70 & 0.49 \\
3 & affinity among members & 4.11 & 0.62 & 0.38 \\
4 & exercising of power & 4.21 & 0.64 & 0.41 \\
5 & relation control & 3.88 & 0.86 & 0.73 \\
6 & Mediation & 3.58 & 1.09 & 1.19 \\
7 & arbitration & 4.15 & 0.68 & 0.46 \\
8 & Consultation & 2.51 & 1.32 & 1.74 \\
\hline
\end{tabular}

Table 3 shows frequency calculation and percentage frequency calculation of the Infallibles' usage of interpersonal and in-group conflict resolution techniques in 70 Hadith and historical documents. 
Table 3 .

\begin{tabular}{clcc}
\hline No. & $\begin{array}{c}\text { Techniques of interpersonal and } \\
\text { in-group conflict resolution }\end{array}$ & $\begin{array}{c}\text { Frequency } \\
\text { calculation }\end{array}$ & $\begin{array}{c}\text { Percentage } \\
\text { Frequency } \\
\text { calculation }\end{array}$ \\
\hline 1 & Tolerance & 12 & 17.14 \\
2 & Negotiation & 14 & 20 \\
3 & affinity among members & 9 & 12.86 \\
4 & exercising of power & 9 & 12.86 \\
5 & Mediation & 10 & 14.28 \\
6 & Arbitration & 7 & 10 \\
7 & Consultation & 9 & 12.86 \\
Total & & 70 & 100 \\
\hline
\end{tabular}

Figure 1 shows the percentage abundance of the infallibles' interpersonal and in-group conflict resolution in 70 Hadith and historical documents.

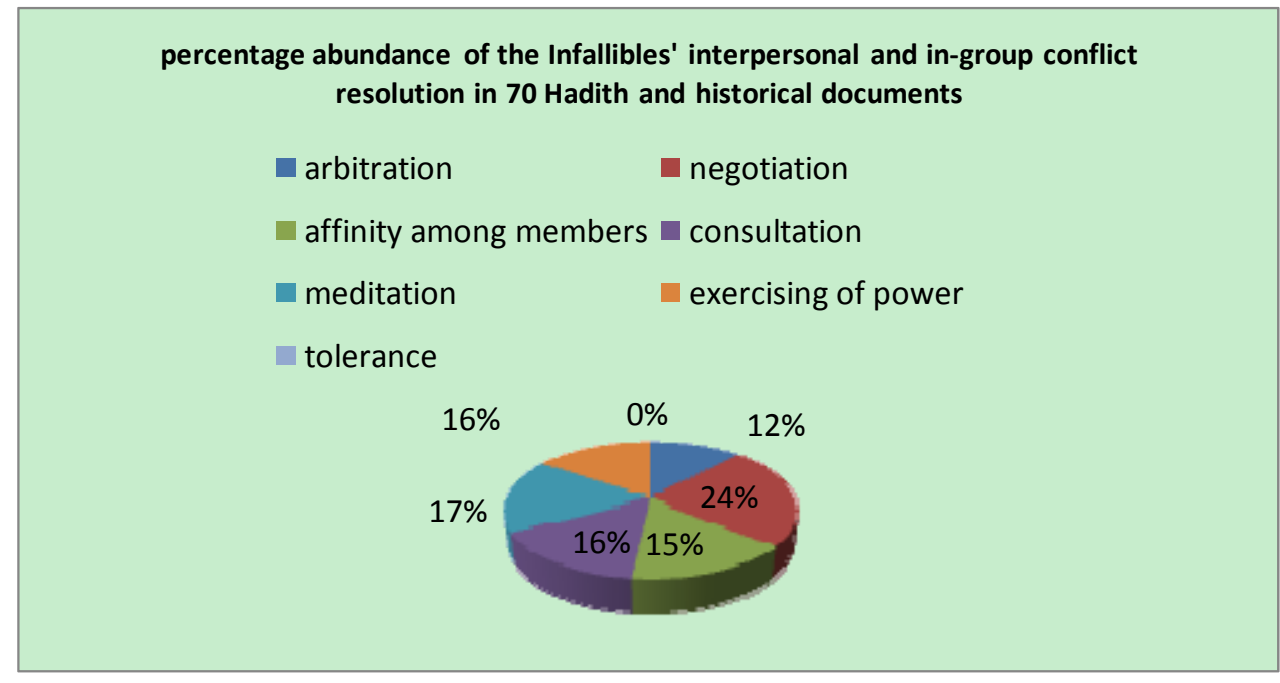

Figure 1.

Figure 2 shows the percentage abundance of the infallibles' interpersonal conflict resolution in 57 Hadith and historical documents.

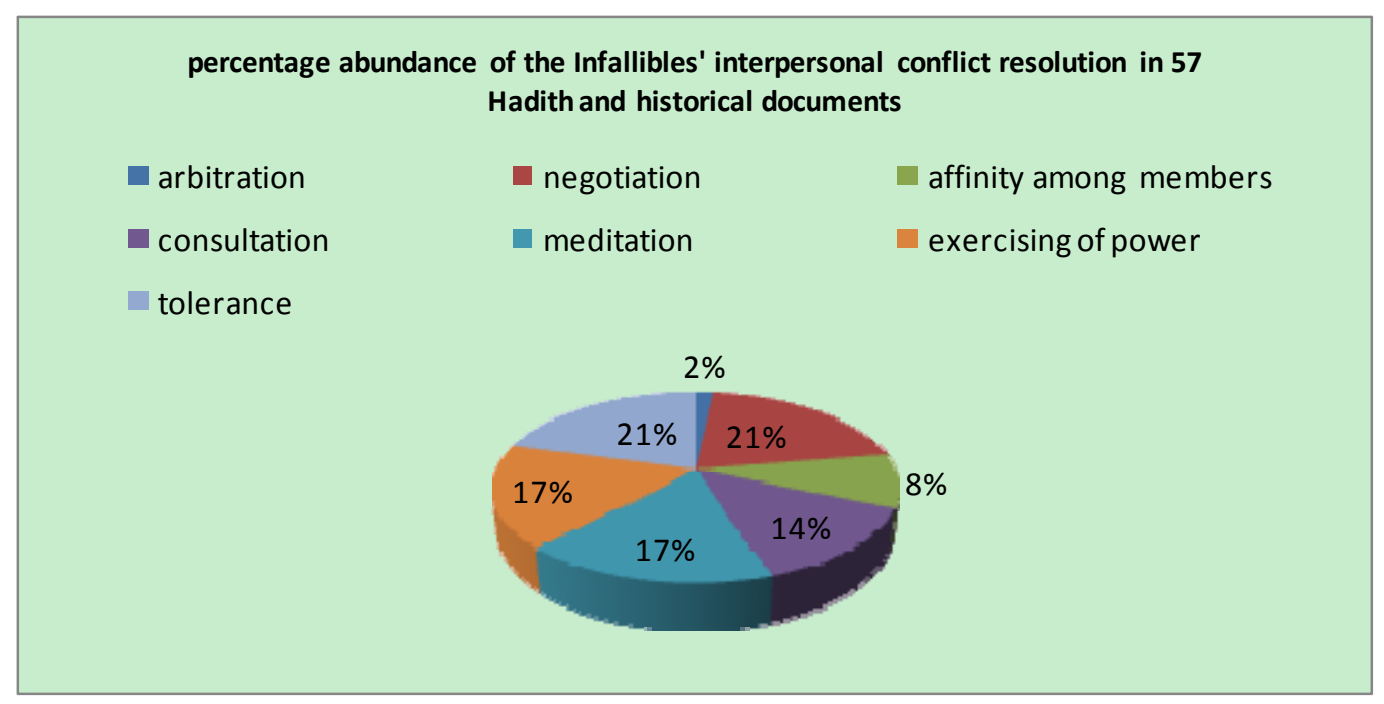

Figure 2. 
Figure 3 shows the percentage abundance of the infallibles' in-group conflict resolution in 13 Hadith and historical documents

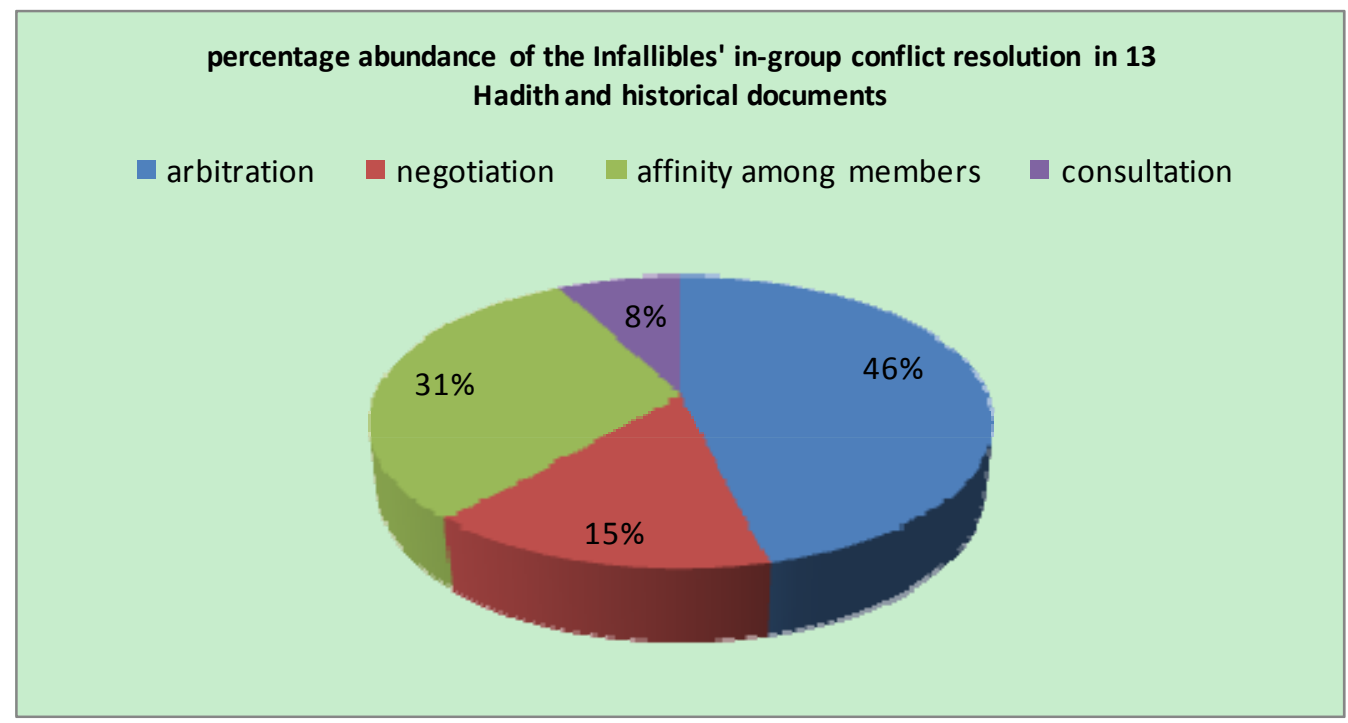

Figure 3.

\section{Conclusion}

The study of 99 selected documents shows that 70 documents mentioned interpersonal and in-group aggressions. The percentage abundance of seven styles of conflict resolution includes: tolerance styles \%17.14, negotiation style $\% 20$, affinity among members style $\% 12.86$, exercising of power style $\% 12.86$, mediation style $\% 14.28$, arbitration style $\% 10$ and consultation style $\% 12.86$.

57 Hadith and historical of this research are related to interpersonal conflicts. The percentage abundance of the Infallibles' usage of conflict resolution techniques is as follows: tolerance styles $\% 19.30$, negotiation style \%8.77, affinity among members style $\% 17.54$, exercising of power style $\% 17.54$, mediation style $\% 17.54$, arbitration style $\% 1.75$ and consultation style $\% 14.03$.

13 Hadith and historical of this research are related to inter-group conflicts. The percentage abundance of the Infallibles' usage of conflict resolution techniques is as follows: negotiation style \%15.38, affinity among members style \% 30.77, arbitration style \%46.15 and consultation style \%7.69.

Descriptions of seven conflict resolution techniques of the Infallibles are as follows:

\subsection{Tolerance}

The result shows that the Infallibles used tolerating against inappropriate behavior, ignoring the mistakes, forgiveness without blaming, behaving in a friendly way with opposite party and etc... for conflict resolution.

\subsection{Negotiation}

The Infallibles used some activities such as choosing the empowered people for negotiation, keeping away from useless negotiation, quieting the opposite party before negotiation, having self confidence and no fear from the anger of opposite party, using simple and understandable examples for the opposite party, listening to the arguments and problems of the opposite party, proposing the solution for conflict resolution and etc...in order to solve the conflict.

\subsection{Affinity among Members}

The Infallibles applied some ways to solve the conflict as follows: hastening the conflict resolution among the brothers of faith or relatives, attempting to solve the conflicts between relatives despite lots of involvements, reminding the Quranic verses about keeping family ties, having friendly behavior with their opponent relatives and etc....

\subsection{Exercising of Power}

The Infallibles accomplished some activities before and while using the exercising of power: compromising on the subaltern opponents, negotiating the subaltern opponents, inviting them to rapprochement and peacekeeping, 
warning to the offenders, punishing the wrongdoer, exercising of power in order to adjudicate, exercising of power in order to support innocent and etc... .

\subsection{Meditation}

The Infallibles applied some activities in order to mediate in conflicts: communicating with parties, volunteering to establish peace among conflict parties, listening to them and transferring it to the other side, giving advice on both sides, tracking of mutual obligations, reducing stress and managing crisis and etc...

\subsection{Arbitration}

The Infallibles applied the following ways in conflict resolutions: choosing the puissant people for judging, agreeing in choosing sentence, determining judges' name, specifying the length of arbitration, specifying the place of arbitration, establishing armistice between the parties and etc... .

\subsection{Consultation}

The Infallibles utilized the following ways in consultation: choosing the consulter with mental, scientific, social and individual moral competence, expressing the issue with the consulter, respecting to consulter, listening to consulter's view, guiding consultant sincerely, introducing the consultant to other consulters in case of lacking knowledge on the subject and etc... .

\section{References}

Abolma'ali, Khadijeh. (2010). Theories of Criminology and Delinquency: with Emphasis on Social Cognition. Tehran: Arjmand Publication (Nasle Farda).

Azarbayjani M., Salarifar M. R., Abbasi A., Kaviani M., \& MousaviAsl S. M., Under supervision of Hojatol eslam Taghavi, \& Mohamad Karim Khodapanahi. (2004). Social psychology: with Approach to Islamic Sources. Tehran. Samt Publication.

Berger, Kathleen. S. (2006). The Developing Childhood and Adolescence ( $7^{\text {th }}$ ed.). USA: Worth Publisher.

Corsini, Raymond. (2002). The Dictionary of Psychology. London: Brunner/Routledge. Taylor \& Francis Group.

Domitrovich, Celene. E., \& Greenberg, Mark. T. (2003). Preventing Interventions that Reduce Aggression in Young Children. In Tremblay, RG, \& Peters, RDeV (Eds.), Encyclopedia on Early Childhood Development (pp. 1-8). Montreal, Quebec: Centre of Excellence for Early Childhood Development.

Petterson, Charlotte. (2008). Child Development. New York: McGraw Hill.

Ramirez, M. J. (1998). Aggression. In Greenberg.G., \&Haraway. M. (Eds.), Comparative Psychology: A Handbook. New York: Garland.

Ramirez, M. J. (2000). Agression: unenfoque Psicobiologico. Valencia: Promolibro.

Ramirez, M. J. (2003). Human Aggression: A Multifaceted phenomenon. Madrid: Centreur.

Ramirez, M. J., \& Ranada, F. A. (1996). De la Agression a la Guerra Nuclear. Oviedo.

Touzandehjani, Hassan, \& colleagues. (2002). Investigating Relative effectiveness of Cognitive-Behavioral Treatments in Controlling. Payame Moshaver quarterly Journal, 7, 112-118.

Woolfolk, Anita. (2004). Educational Psychology ( $9^{\text {th }}$ ed.). Allyn \& Bacon. 